\title{
Toward Gamification to Software Engineering and Contribution of Software Engineer
}

\author{
Wei Ren \\ Trinity College Dublin \\ Trinity College Dublin, \\ Dublin, Ireland \\ +353876805384 \\ renw@tcd.ie
}

\author{
Stephen Barrett \\ Trinity College Dublin \\ Trinity College Dublin, \\ Dublin, Ireland
}

\author{
Sourojit Das \\ Trinity College Dublin \\ Trinity College Dublin, \\ Dublin, Ireland
}

\begin{abstract}
We wish to change developers' behaviors to increase software engineering efficiency and the previous research shows that gamification method can change user's behaviors. Gamification has become a popular topic in many areas including software engineering. We sum up some pairs of gamification features which can influence people's specific behavior like engagement. Thus, we build a general gamification processing model for software development life cycle. Also, we built a metrics model of software engineers' contribution based on gamification processing model for gamifying software engineer's contribution. The next step, we will gamify the contribution of software engineers to change engineer's behaviors for converting junior software engineers to senior software engineers.
\end{abstract}

\section{CCS Concepts}

- Software and its engineering $\rightarrow$ Software creation and management $\rightarrow$ Software development process management $\rightarrow$ Software development $\operatorname{methods} \rightarrow$ Design patterns

\section{Keywords}

Gamification Feature Pairs, Gamification Processing Model, Measurement Contribution of Software Engineer.

\section{INTRODUCTION}

\subsection{Previous Research of Gamification}

In this paper, we will try to find methods to change software engineer's behavior for increasing software development efficiency. Gamification is a new idea in software engineer area that it will influence software development processing and we do some literature review for gamification. Recent years, gamification has become a popular topic. The basic concept of gamification in computer science area was issued in CHI2011(International conference of Human-Computer Interaction) which defined using game design elements in nongaming contexts [1]. There are lots examples proving gamification can work in complex systems from different disciplines such as

Permission to make digital or hard copies of all or part of this work for personal or classroom use is granted without fee provided that copies are not made or distributed for profit or commercial advantage and that copies bear this notice and the full citation on the first page. Copyrights for components of this work owned by others than ACM must be honored. Abstracting with credit is permitted. To copy otherwise, or republish, to post on servers or to redistribute to lists, requires prior specific permission and/or a fee. Request permissions from Permissions@acm.org.

ICMSS 2020, January 17-19, 2020, Wuhan, China

(C) 2020 Association for Computing Machinery.

ACM ISBN 978-1-4503-7641-9/20/01 ..\$15.00

DOI: https://doi.org/10.1145/3380625.3380628 education, online social community, business as well as software engineering. As google scholar and Scopus shows, we can find that the numbers of paper related to gamification increased rapidly (see Figure 1). The previous research [2] outcomes show that gamification will influence users' psychological and behavioral outcomes. These results also indicate gamification provides positive effects. Gamification is touted as a next generation method for marketing and customer engagement in popular discussion [2] and it has become an important part of software engineering development $[3,4]$. In software engineering area, one of the main tasks is to enhance software efficiency and increase the software engineer's ability [3]. As gamification has positive influence in users' psychological and behavioral, thus we believe that gamification is a good method to improve software engineering performance and software engineer's performance.

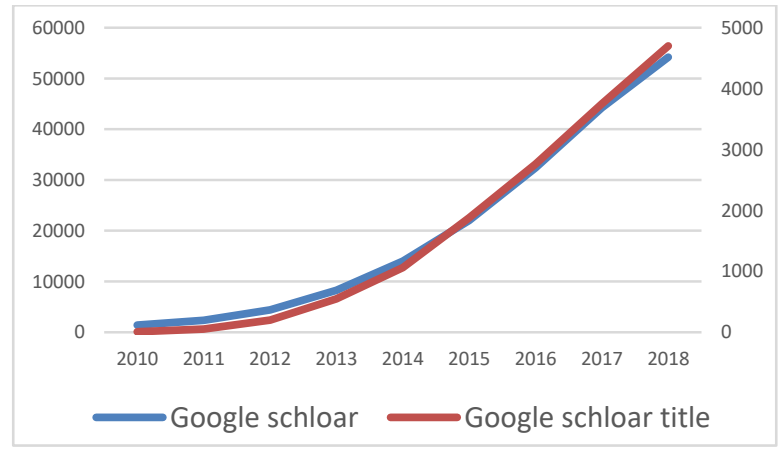

Figure 1. Search Result of Gamification

Gamification primarily goals is to increase users' or developers' motivation, engagement and participation towards activities, learning knowledge or using new technology. So, gamification can increase the activities or processing efficiency [3-6]. Gamification has been used in many subjects including education [7-10], business[11] and software engineering. Researchers are confident that gamification can change human behaviors. Education area and business area use some mature framework such as 6D, MDA [12] and Octalysis [13]. Recent research in software engineering field synthesizing the current gamification design methods and detailed method for engineering of gamified software [14]. They adapt DSR (design science research) method to get knowledge of methods fragments and assemble method fragments to evaluation. Finally, they got 13 design principles and a model. However, this model is not a general model for software development life cycle. Another gap is that most research on gamification focus on quantity rather than quality. Gamification designers designs game mechanics (such as badges, leaderboards and points) based on quality rather than quantity. We use gamification do quantitative analysis for software development. 
Gamification is designed by some similar steps currently, the most common steps are: 1) analysis which group of people need to be gamified and weather they can be gamified; 2) find the suitable psychology theory to support them that gamification will work in their activities; 3) select appropriate feature of gamification which can use in their activities; 4) select tools that they will use during their activities; 5) evaluation their results based on data of questionnaire, experts survey. Software engineering prefer to use these five design steps.

\subsection{Gamification Feature Pairs}

Based on our literature review, we find that gamification will change people's behaviors. We wish to find the specific gamification feature can influence specific behaviors. Gamification has ten features [15]. We will focus gamification features and find that what feature can do. Among these features, the most popular feature is points. And there is an interesting phenomenon that all these researches use points will also use leaderboard [16-31] and these researches try to increase user's motivation and participation. They will use points as a standard to critical their job and using leaderboard to reflect their points. The points can clearly reflect the difference of users and leaderboard will help them to find their position in the team. Thus, points and leaderboard are an efficiency pair to increase user's motivation. The reason that this pair work is based on self-determination theory (SDT), a psychology principle.

Another pair is rewards and achievements or badges. Researchers use this pair to increase user's engagement [32,24,25,29-31]. When people finish some tasks and they will get rewards like badges or getting some achievement milestones. They use achievements or badges for simulating people to keep focus on the projects or systems. Thus, this pair, achievements and rewards, can increase users' engagement and participation.

Challenge and feedback are a pair for increasing users' motivation and participation [18,20,22,26,27,29-31]. Some researchers will set challenges for users and give feedback when they finish challenges. This pair can work based on role-motivationinteraction (RMI) theory. When users have clear goal, they can more focus on their projects to increase their concentration [3336,25,27,29-31]. These gamification features pair and features can affect users' behavior in their projects or systems. Therefore, many researchers adapt more than one pair to create their gamification methods to hit their target. The generally steps as follow: setting a basic guidance, selecting gamification features and analysis the results based on users' questionnaire or survey.

We will provide clear metrics to determine the result after using gamification. We provide a metrics determine result of gamify software engineers' contribution based on data driven. We quantify gamification mechanisms to find effective gamification features in software engineers' contribution. A few papers provide quantitative result of gamification mechanisms in software engineering area [38] or practical guidance on designing gamification [39]. The most gamification frameworks or processing have been developed in a non-data driven environment. As the theoretical and practical field of gamification is growing rapidly, it is necessary to develop quantitative gamification methods of software engineering that handle gamification challenges as they grow.

Therefore, in this paper, we try to build a general gamification model for software development life cycle and provide a quantitative metrics of contribution of software engineers. The next step of our work is to gamify developer's work based on the gamification model and quantitative analysis their contribution based on contribution metrics to leading them from junior engineers to senior engineers.

\section{GAMIFICATION PROCESSING MODEL}

As discussed in previous sections, gamification in software development life cycle need a general processing model. Thus, the aim of this part is to produce a processing model for whole development life cycle, as well as give the instruction for detail. Gamification model for software development is combined with four parts which are preparation, platform, gamification design and development. (See figure 2)

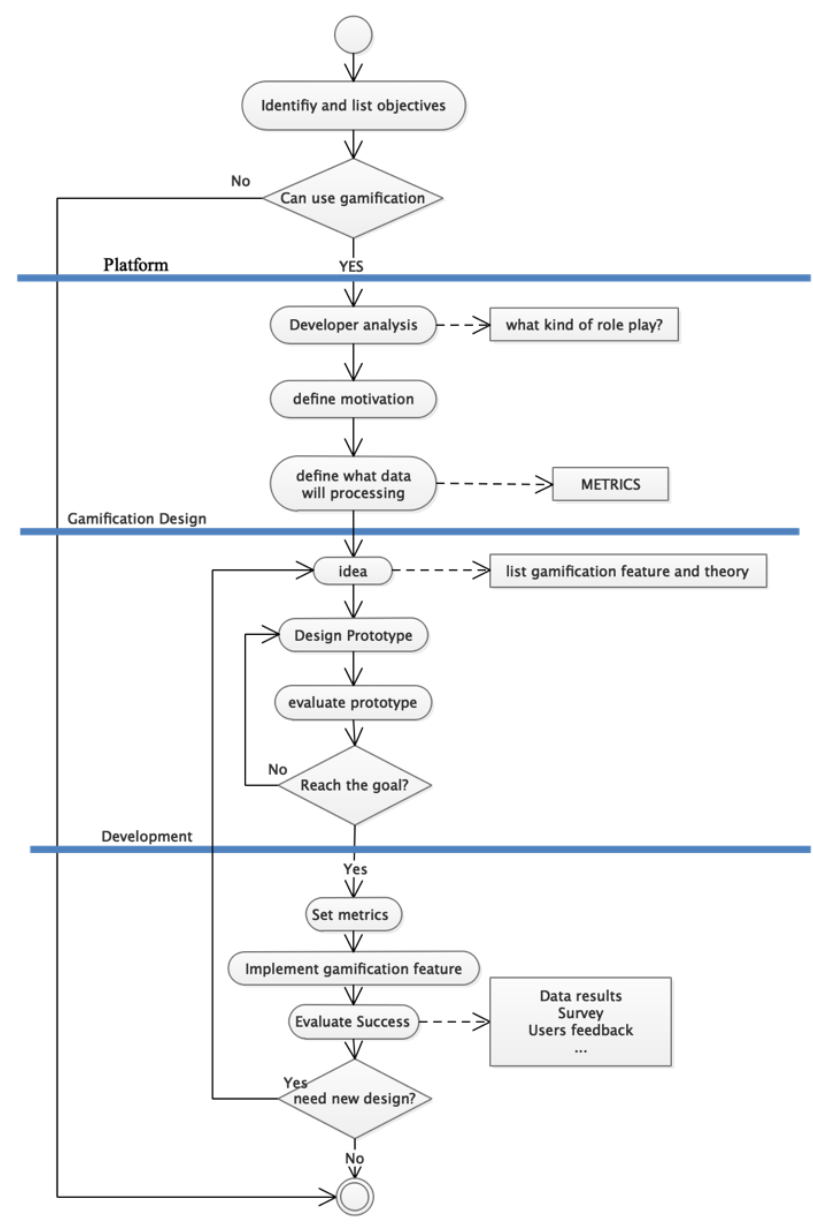

Figure 2. Gamification Model

\subsection{Preparation}

In this part, there are five steps and at the end, the model will move to the platform part.

Identify and list objectives: This is the first step for all processing and people will identify and list their objectives such as team information, project information and other basic things. In this step, we also need to define gamification level. Developers need to define which gamification level they can apply based on CMM and game maturity model [28]. As they define the level, this can help them to gamify appropriate parts of their development. After that, developers will select their methodology and check whether the methodology suitable for gamification. For example, waterfall model in software engineering is not suitable for feedback strategy as the model is linear. For the first judgement part: Can use 
gamification? This part means when developers decide software engineering methodology, they can determine whether this methodology fit for gamification. If not, they can skip gamification and keep using original way to processing software development.

\subsection{Platform}

We base our approach on the software engineering intelligence field, which seeks to measure the performance of software engineering teams in the delivery of the software codebase. As software teams work, they collaborate using a range of engineering tools, both technical and social, that provide detailed and valuable data regarding the process of software construction as it happens. Such measures range from metrics that capture code quality on a commit by commit basis, to measures that record the pace individual and teamwork, collaboration in problem solving and many other aspects of the complex engineering process. Thus, in this part, we define two pipeline which are developers and project.

Developer analysis: This step will help project manager to define different role for developers. Developers' role could be requirement analysis, function programmer or testers. Define motivation: based on developers' role, project manager can define their motivation type such as increase engagement of programing or encourage to do more requirement analysis. Define processing data: When manager define the motivation type, he or she could decide to select appropriate gamification metrics and define which metrics would be used. Also, the metrics would be decided by developers' pipeline and project pipeline. Then, different features will be assigned to different roles. For example, testers will get point if they test code and programmers will get point if their code pass the test and the point will be given by testers.

\subsection{Gamification Design}

In this part, we will use gamification feature to create a gamification environment for developers. There are five steps in gamification design part.

Idea: manager can list all suitable gamification features and theory based on previous parts such as points, leaderboard, guide, reward, etc. Manager compose these features to a reasonable story and set clear goals or guides. Developers will follow the story to work and the story can help to lead their behavior. Design prototype: Manager processes the prototype to make sure it works. Reach the goal: In this step, manager judges prototype result and if it works as we expect, we can move forward to the next step or back to design prototype step to re-design the prototype. Once prototype work well, we will develop the full gamification processing model during development to lead developer working in a better way.

\subsection{Development}

In this part, developers will develop their project in a gamification environment to help them improving their software performance.

Set Metrics: As developers have selected their developing tools and platform, we will set appropriate metrics for them. Implement gamification feature: we will set gamification feature on metrics such as developers will get one point if their smell code scores drop one. Evaluate success: check developer's performance based on metrics to check whether gamification provide positive effect. Also, we can do some survey for developers and get their feedback. Need new design: If gamification meets manager's requirement, we can move on or back to design prototype step.

\section{CONTRIBUTION OF SOFTWARE ENGINEER}

We try to change software engineer's behaviors by gamification based on previous work. There are lots of things in software engineering can be measure by specific metrics. We decide to gamify the contribution of software engineer for changing their behavior. We use a constructed data-model to calculate the contribution of a software engineer to a software project through signals obtained from an open-source project repository such as GitHub. We use the platform that would quantify the contribution of a software developer using the metrics derived from the selected GitHub and Gitter signals. Then, we evaluate the datamodel through a sanity test of the contribution values generated by the tool with the values estimated by a human expert. We are trying to build a bug-free codebase.

The contribution of software engineer can divide to three part which are direct contribution, administrative contribution and guidance contribution. There are different metrics to measure contribution. Now, we focus on more specific area in contribution of software engineer. We try to build a bug-free codebase. Thus, we will more focus on pull-request and issues area.

\section{NEXT STEP}

We will test our gamification model for developers and different level software engineers. We wish to change their behaviors and performance through gamification. Based on our previous research that we find gamification can change people's behaviors and we believe it can work on software engineers for balancing their contribution. For future work, we will introduce gamification features and strategy to software engineer's development life cycle, such as using points and leaderboard to contribution of issue administration.

\section{CONCLUSION}

This paper introduces gamification and how we believe it can use for software engineering. Then, we build a model for processing gamification in software engineering life cycle. We decide to gamify contribution of software engineers and we will design the experiment future to see the result.

\section{REFERENCES}

[1] Deterding, Sebastian, et al. "Gamification. using gamedesign elements in non-gaming contexts." CHI'11 extended abstracts on human factors in computing systems. 2011. 2425-2428.

[2] J. Hamari, [J. Koivisto and H. Sarsa, "Does Gamification Work? - A Literature Review of Empirical Studies on Gamification," 2014 47th Hawaii International Conference on System Sciences, Waikoloa, HI, 2014, pp. 3025-3034.

[3] J. Hamari, J. Koivisto, H. Sarsa, Does gamification work?-a literature review of empirical studies on gamification, Proc. 47th Hawaii Int. Conf. Syst. Sci. Hawaii, IEEE, 2014, pp. 3025-3034, , http://dx.doi.org/10.1109/HICSS.2014.377.

[4] O. Pedreira, F. García, N. Brisaboa, M. Piattini, Gamification in software en- gineering - a systematic mapping, Inf. Softw. Technol. 57 (2015) 157-168, http://dx.doi.org/10.1016/j.infsof.2014.08.007.

[5] K. Huotari, J. Hamari, A definition for gamification: anchoring gamification in the service marketing literature, Electron. Mark. 27 (2017) 21-31, http://dx.doi.org/ $10.1007 / \mathrm{s} 12525-015-0212-\mathrm{z}$. 
[6] J. Hamari, J. Koivisto, Why do people use gamification services? Int. J. Inf. Manage. 35 (2015) 419-431, http://dx.doi.org/10.1016/j.ijinfomgt.2015.04.006.

[7] P. Denny, The effect of virtual achievements on student engagement, Proc. SIGCHI Conf. Hum. Factors Comput. Syst. - CHI '13, New York, New York, USA, ACM Press, 2013, pp. 763-772, http://dx.doi.org/10.1145/2470654.2470763.

[8] L. Hakulinen, T. Auvinen, A. Korhonen, Empirical study on the effect of achieve- ment badges in TRAKLA2 online learning environment, Learn. Teach. Comput. Eng. Macau, IEEE, 2013, pp. 47-54, http://dx.doi.org/10.1109/LaTiCE.2013.34.

[9] J. Hamari, D. Shernoff, E. Rowe, B. Coller, T. Edwards, Challenging games help students learn: an empirical study on engagement, flow and immersion in game- based learning, Comput. Human Behav 54 (2016) 170-179, http://dx.doi.org/10. 1016/j.chb.2015.07.045.

[10] R.N. Landers, Developing a theory of gamified learning: Linking serious games and gamification of learning, Simul. Gaming. 45 (2014) 752-768, http://dx.doi.org/10. $1177 / 1046878114563660$.

[11] Juho Hamari, Transforming homo economicus into homo ludens: A field experiment on gamification in a utilitarian peer-to-peer trading service, Electronic Commerce Research and Applications, Volume 12, Issue 4, 2013.

[12] Klock, A., \& da Cunha, L. (2015). Gamification in e-learning systems: A conceptual model to engage students and its application in an adaptive e-learning system. In Learning and collaboration technologies (Vol. 9192, pp. 595-607). Berlin: Springer.

[13] Chou, Y.-K. (2015). Actionable gamification : Beyond points, badges, and leaderboards. Fremont: Octalysis Media.

[14] Benedikt Morschheuser, Lobna Hassan, Karl Werder, Juho Hamari, How to design gamification? A method for engineering gamified software, Information and Software Technology, Volume 95, 2018, Pages 219-237.

[15] Jonna Koivisto, Juho Hamari, Demographic differences in perceived benefits from gamification, Computers in Human Behavior, Volume 35, 2014, Pages 179-188.

[16] Siutila, M. (2018). The gamification of gaming streams. GamiFIN2018.

[17] Bianchini, Devis et al. "TAB Sharing: A Gamified Tool for e-Participation.” AVI (2016).

[18] Nah, Fiona \& Zeng, Qing \& Rajasekhar Telaprolu, Venkata \& Padmanabhuni Ayyappa, Abhishek \& Eschenbrenner, Brenda. (2014). Gamification of Education: A Review of Literature. 401-409.

[19] Devis Bianchini, Daniela Fogli, and Davide Ragazzi. 2016. Promoting Citizen Participation through Gamification. In Proceedings of the 9th Nordic Conference on HumanComputer Interaction (NordiCHI '16). ACM, New York, NY, USA, Article 8, 4 pages.

[20] Francisco-Aparicio, A., Gutie' rrez-Vela, F. L., Isla-Montes, J. L., \& Sanchez, J. L. G. (2013). Gamification: Analysis and application. In New trends in interaction, virtual reality and modeling (pp. 113-126). Springer London.
[21] E. D. Santos and S. R. B. Oliveira. 2018. Gamification and Evaluation the Use of the Function Points Analysis Technique in Software Quality Subjects: The Experimental Studies. In Proceedings of the 17th Brazilian Symposium on Software Quality (SBQS). ACM, New York, NY, USA.

[22] Amal A. Albilali, Rizwan J. Qureshi. 2016 Proposal to Teach Software Development Using Gaming Technique. International Journal Modern Education and Computer Science, 2016, 8, 21-27.

[23] Naomi Unkelos-Shpigel and Irit Hadar. 2015. Gamifying software engineering tasks based on cognitive principles: the case of code review. In Proceedings of the Eighth International Workshop on Cooperative and Human Aspects of Software Engineering (CHASE '15). IEEE Press, Piscataway, NJ, USA, 119-120.

[24] Elgrably, I. And Oliveira, S. 2018 Gamification and Evaluation of the Use the Agile Tests in Software Quality Subjects: The Application of Case Studies. In Proceedings of the 13th International Conference on Evaluation of Novel Approaches to Software Engineering (ENASE 2018), pages 416-423

[25] Isaac Chow and LiGuo Huang. 2017. A Software Gamification Model for Cross-Cultural Software Development Teams. In Proceedings of the 2017 International Conference on Management Engineering, Software Engineering and Service Sciences (ICMSS '17), Yulin Wang (Ed.). ACM, New York, NY, USA, 1-8.

[26] Félix García, Oscar Pedreira, Mario Piattini, Ana CerdeiraPena, Miguel Penabad, A framework for gamification in software engineering, Journal of Systems and Software, Volume 132, 2017, Pages 21-40.

[27] J. Dubois, Daniel \& Tamburrelli, Giordano. (2013). Understanding gamification mechanisms for software development. 659-662.

[28] Chow, Isaac, and LiGuo Huang. "A software gamification model for cross-cultural software development teams." Proceedings of the 2017 international conference on management engineering, software engineering and service sciences. 2017.

[29] Morschheuser, Benedikt, Juho Hamari, and Jonna Koivisto. "Gamification in crowdsourcing: a review." 2016 49th Hawaii International Conference on System Sciences (HICSS). IEEE, 2016.

[30] V. Uskov and B. Sekar, "Gamification of software engineering curriculum," 2014 IEEE Frontiers in Education Conference (FIE) Proceedings, Madrid, 2014, pp. 1-8.

[31] Juho Hamari, Transforming homo economicus into homo ludens: A field experiment on gamification in a utilitarian peer-to-peer trading service, Electronic Commerce Research and Applications, Volume 12, Issue 4, 2013.

[32] Li, Xiaozhou. "A method to support gamification design practice with motivation analysis and goal modeling." GamiFIN (2018).

[33] Herranz, Eduardo \& Colomo-Palacios, Ricardo \& de Amescua, Antonio. (2015). Gamiware: A Gamification Platform for Software Process Improvement. 127-139.

[34] Simõ es, J., D' iaz Redondo, R., \& Ferna ndez Vilas, A. (2012). A social gamification framework for a K-6 learning platform. Computers in Human Behavior, 29(2), 345-353. 
[35] Nah, F.-H., Telaprolu, V., Rallapalli, S., \& Venkata, P. (2013). Gamification of education using computer games. In S. Yamamoto (Ed.), Human interface and the management of information. Information and interaction for learning, culture, collaboration and business. JOUR, Springer Berlin Heidelberg.

[36] Wongso, O., Rosmansyah, Y., \& Bandung, Y. (2015). Gamification framework model, based on social engagement in e-learning 2.0. In Proccedings of the 2 nd international conference on technology, informatics, management, engineering and environment (TIME 2014), Bandung, Indonesia (pp. 10-14). IEEE.

[37] DiTommaso, D. (2011). Beyond gamification: Architecting engagement through game design thinking. Retrieved February 9, 2015.
[38] Isaac Chow and LiGuo Huang. 2017. A Software Gamification Model for Cross-Cultural Software Development Teams. In Proceedings of the 2017 International Conference on Management Engineering, Software Engineering and Service Sciences (ICMSS '17), Yulin Wang (Ed.). ACM, New York, NY, USA, 1-8.

[39] Christian R. Prause and Matthias Jarke. 2015. Gamification for enforcing coding conventions. In Proceedings of the 2015 10th Joint Meeting on Foundations of Software Engineering (ESEC/FSE 2015). ACM, New York, NY, USA, 649-660 